Daniela Leandro Rezende Universidade Federal de Viçosa, Viçosa, MG, Brasil

\title{
Desafios à representação política de mulheres na Câmara dos Deputados
}

Resumo: Este artigo discute os desafios à representação política de mulheres na Câmara dos Deputados. Argumento que à demanda pela eleição de mais mulheres deve ser agregada a discussão sobre as regras e procedimentos que regulam sua atuação, uma vez que essas podem limitá-la ou torná-la mais efetiva do ponto de vista da representação de mulheres. Avaliando a distribuição de recursos legis/ativos (vagas em comissões legis/ativas e presidências de comissões e da Mesa Diretora) entre legisladoras e legisladores, pode-se constatar que essa ocorre de forma desigual. Apesar disso, destaca-se positivamente a criação da Secretaria da Mulher, instância que pode potencializar a atuação das legisladoras, mitigando os efeitos decorrentes dessas constituírem uma "pequena minoria". Por fim, argumento que o desafio de eleger mais mulheres deve se articular à necessidade de garantir que às mulheres já eleitas sejam assegurados recursos que potencializem mudanças que garantam maior presença de mulheres nos espaços de poder e decisão.

Palavras-chave: gênero; poder legislativo; representação política de mulheres

Não é suficiente que se eleja muitas mulheres; o passo seguinte é propiciar condições de trabalho e influência para essas mulhere Drude Dahlerup (1993, p. 185-186 [tradução livre])

Se as novas representantes não tiverem espaço para expressar algo além da política partidária existente, sua inclusão se torna apenas simbólica - o que é relevante, mas de alguma forma menos que o esperado Anne Phillips (1995, p. 188 [tradução livre])

\section{Introdução}

A histórica exclusão das mulheres das esferas de poder e tomada de decisão foi abordada em diversos tratados e conferências internacionais ${ }^{1}$ e fundamenta as lutas pela

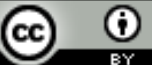

Esta obra está sob licença Creative Commons.

' Ver Maria Luiza Ribeiro VIOTTI (2006). 
garantia de direitos políticos como os direitos de votar e de se eleger. Entretanto, sabe-se que a existência formal desses direitos não assegura às mulheres participação equitativa nos espaços de poder, o que leva a que sua ampla participação na política não institucional conviva com sua escassa presença na política formal. Diante desse quadro, a Plataforma de Ação de Beijing de 1995 (VIOTTI, 2006), especificamente com relação à participação das mulheres em espaços de poder e tomada de decisões, define como objetivo estratégico a adoção de "medidas para garantir às mulheres igualdade de acesso às estruturas de poder e ao processo de decisão e sua participação em ambos" (VIOTTI, 2006, p. 216). Dentre as medidas a serem adotadas para alcançar este objetivo, destacam-se o estabelecimento de ações afirmativas, de forma a promover uma "massa crítica" de mulheres dirigentes nos setores público e privado, e o desenvolvimento de ações de formação que estimulem e habilitem as mulheres a ocuparem postos de direção.

Considerando mais especificamente o poder Legislativo brasileiro, tais objetivos fundamentaram a adoção de mecanismos de ações afirmativas, como cotas de gênero em listas eleitorais e a reserva de recursos do Fundo Partidário para a criação e veiculação de programas de promoção e difusão da participação política feminina (Leis federais 9.100/1995, 9.504/1997 e 12.034/2009). Infelizmente, tais iniciativas têm sido insuficientes para garantir a inserção das mulheres em espaços de poder, vide a estabilidade do baixo percentual de eleitas para a Câmara dos Deputados (Clara ARAÚJO, 2001, 2005, 2009, 2010; ARAÚJO; José Eustáquio Diniz ALVES, 2007; ALVES; Suzana CAVENAGHI, 2013; Marlise MATOS, 2010, 2012). Verifica-se, pois, que a existência de cotas, apesar de necessária, não é suficiente para garantir a eleição de maior contingente de mulheres ou a transformação ou reorganização das instituições políticas em direção à igualdade de gênero, e tampouco a possibilidade de que as mulheres eleitas possam influenciar o processo decisório.

Entretanto, as estratégias de promoção da igualdade de gênero no Legislativo não se limitam à eleição de mais mulheres, como indica pesquisa da Inter-Parliamentary Union (Julie BALLINGTON, 2008) realizada com legisladoras e legisladores de 110 países, que aponta quatro fatores decisivos: o apoio do partido (ou coalizão) governante; o trabalho de comissões legislativas; a atuação de bancadas femininas; e as regras que organizam o funcionamento do Legislativo. Dessa forma, pode-se dizer que a concretização da igualdade de gênero demanda, além da eleição de mulheres, a garantia de que essas possam, de fato, influenciar o processo decisório, com o objetivo de disseminar uma perspectiva de gênero ${ }^{2}$ nas políticas públicas resultantes do processo legislativo. Nesse sentido, o presente artigo parte do pressuposto de que a maior ou menor capacidade das legisladoras em influenciar o processo decisório no Legislativo é requisito importante para garantir transversalidade de gênero à representação política de mulheres.

Essa garantia estaria, portanto, relacionada ao acesso a recursos legislativos, distribuídos segundo as regras que organizam o trabalho legislativo, e à formação de uma identidade coletiva entre as legisladoras, que tornaria possível sua ação coordenada.

Partindo do exposto, o objetivo deste artigo é avaliar os desafios à representação política de mulheres impostos por características do poder Legislativo, mais especificamente pela organização da Câmara baixa brasileira. Para tanto, ele está organizado em três seções, além desta breve Introdução: a primeira seção apresenta o marco analítico que orienta a investigação. Partindo da revisão da "teoria da massa crítica", argumento que esta deve ser combinada à discussão sobre direitos de minorias políticas. Na segunda seção, é apresentada a metodologia e são discutidos os dados relativos à Mesa Diretora e comissões legislativas, à integração das comissões permanentes, à

${ }^{2}$ Para a discussão sobre representação de perspectivas, ver Iris Marion YOUNG (2002). 
organização da bancada feminina da Câmara dos Deputados, que indicam que o arranjo institucional existente não favorece as legisladoras, considerando os critérios e resultados da distribuição de recursos políticos. Por fim, na última seção, apresento os desafios à superação da desigualdade de gênero na Câmara dos Deputados, à luz dos dados apresentados e do contexto mais recente.

\section{Representação política de mulheres e poder legislativo: minoria política e ação coletiva}

O Brasil se encontra na $155^{a}$ posição (no total de 188 posições) no ranking de mulheres em legislativos nacionais da Inter-Parliamentary Union. ${ }^{3}$ A sub-representação de mulheres no país se mantém estável e o percentual de eleitas para a Câmara dos Deputados permanece inferior a 10\% desde a década de 1940. Esse cenário se mantém inalterado a despeito de iniciativas como cotas de gênero nas listas eleitorais e da obrigatoriedade de que os partidos políticos destinem parte de seus recursos ao fomento da participação política de mulheres. Apesar de ineficazes, tais estratégias explicitam a centralidade dos partidos políticos para a eleição de mulheres e seu papel como mediadores da distribuição de recursos eleitorais no Brasil (ARAÚJO, 2005; Maria Luiza Miranda ÁLVARES, 2008; Teresa SACCHET; Bruno W. SPECK, 2012; Fabiano SANTOS; Carolina Almeida de PAULA; Joana SEABRA, 2012; Larissa Peixoto Vale GOMES, 2016).

Diante desse quadro, pode-se afirmar que, a despeito dos avanços alcançados na discussão sobre cotas eleitorais como importante mecanismo de inclusão de mulheres, pouco tem sido discutido sobre as possibilidades e constrangimentos associados à atuação de mulheres no Legislativo brasileiro. ${ }^{4}$ Destaca-se, portanto, a necessidade de enfatizar a organização do processo decisório, o que permitiria avaliar as possibilidades das mulheres eleitas influenciarem as decisões políticas, aspecto explicitado nas citações que compõem a epígrafe deste artigo. Nesse sentido, argumento que à demanda pela eleição de mais mulheres deve ser agregada a discussão sobre as regras e procedimentos que regulam sua atuação, uma vez que essas podem limitá-la (ou, mesmo, anulá-la) ou torná-la mais efetiva do ponto de vista da representação de mulheres. ${ }^{5}$

É premente, pois, questionar a neutralidade com relação a gênero assumida pelas regras que organizam o processo decisório no poder legislativo, considerando que, ainda que não estejam explicitadas em procedimentos formais, estas podem abrir margem para a emergência de regras informais, que cumprem o papel de reproduzir e reforçar a desigualdade de gênero no campo da política (Fiona MACKAY; Meryl KENNY; Louise CHAPPELL, 2010). Esse esforço se baseia nas contribuições do campo de gênero feminista, sendo necessário, pois,

\footnotetext{
${ }^{3}$ Ver WOMEN in national parliaments (dados relativos a 01/07/2016).

${ }^{4}$ Uma exceção é o trabalho de Luana Simões PINHEIRO (2007).

${ }^{5}$ Considerando o debate sobre o tema (Hanna PITKIN, 1967; YOUNG, 2002; PHILLIPS, 1995; Sarah CHILDS; Mona Lena KROOK, 2006; Leslie A. SCHWINDT-BAYER, 2010), é preciso atentar para as controvérsias relativas à noção de representação de mulheres ou representação de gênero. Esta remete a questões difíceis de mensurar, como a ideia de representação substantiva: como verificar que uma parlamentar representa "as mulheres", sem incorrer numa definição essencialista desse grupo? Ademais, uma vez que a representação política/eleitoral possui base geográfica relacionada aos distritos eleitorais, como verificar o vínculo entre representantes e representadas/os quando os interesses em questão não possuem natureza geográfica? Assim, é preciso esclarecer que o objetivo do artigo não é verificar se há uma agenda de gênero ou que políticas as mulheres parlamentares implementarão, mas se é dada a essas a possibilidade de influenciar o processo decisório, considerando sua organização e os recursos a elas disponíveis.
} 
interpelar, re-colocar e re-significar permanentemente os conteúdos e as formas daquilo que se apresenta como contingentemente universal, [...] na constante problematização das hierarquias e das subordinações, na crítica contumaz às opressões de todas as ordens (MATOS, 2008, p. 350).

Essa postura teórico-metodológica demanda que se explicite o lugar destinado às legisladoras no processo legislativo a partir das regras que organizam o processo de tomada de decisões.

Tal estratégia permite considerar a relação entre os grupos de parlamentares, e, mais especificamente, entre maioria e minoria, e os recursos disponíveis para tais grupos no jogo parlamentar, sendo esse aspecto de fundamental importância no que se refere à atuação das mulheres parlamentares, consideradas como um grupo minoritário (como define Drude DAHLERUP, 1993) ou, mais precisamente, uma minoria política (Sarah A. BINDER, 1997).

Com relação ao conceito de minoria, a literatura sobre o poder legislativo trata da relação entre maioria/minoria enfatizando ora o caráter partidário desse recorte, ora as preferências dos/as legisladores/as. Entretanto, gênero não é considerado um marcador relevante no que tange à definição de maioria e minoria. Essa omissão pode ser considerada grave diante do quadro apresentado, por exemplo, por Jutta MARX e Jutta BORNER (2011), que explicitam a configuração generificada dos arranjos institucionais nos legislativos.

Portanto, é preciso considerar que gênero é um princípio de organização do trabalho parlamentar, o que pode indicar a existência de divisão sexual do trabalho legislativo ${ }^{6}$ e a restrição de direitos de minorias fundada em critérios ilegítimos e injustificáveis no contexto das democracias contemporâneas. Assim, se a restrição dos recursos disponíveis às minorias partidárias é aceitável, o mesmo não se pode dizer a respeito das minorias políticas, grupos definidos a partir de características adscritas ou pertencimentos diferentes do partidário, como gênero.

A análise das mulheres enquanto minoria no legislativo tem como referência pioneira a teoria da massa crítica, desenvolvida por Dahrelup (1993). Segundo a autora, tratar as mulheres como grupo minoritário significa considerá-las enquanto minoria numérica que ocupa uma posição subalterna ou desprivilegiada. A questão que se coloca diz respeito, então, à massa crítica necessária para que essa minoria numérica consiga potencializar e mobilizar recursos para transformar a arena legislativa ou à constituição de uma minoria suficiente para influenciar o processo decisório.

Isso leva Dahlerup (1993) a argumentar, tendo como referência a obra de Rosabeth Moss KANTER (1977), que se deve prestar atenção nos números relativos ou à proporção entre grupos sociais, e não apenas no número isolado de mulheres, ${ }^{7}$ em especial no que se refere aos corpos legislativos. A noção de massa crítica se apresenta como fundamental porque estabelece um patamar a partir do qual haveria uma mudança qualitativa rumo à representação de mulheres, subsidiada por uma elevação no percentual de mulheres eleitas:

\footnotetext{
${ }^{6}$ Segundo Danièle KERGOAT (2009, p. 67), "divisão sexual do trabalho é a forma de divisão do trabalho social decorrente das relações sociais de sexo; esta forma é adaptada historicamente e a cada sociedade. [...] Esta forma de divisão social do trabalho tem dois princípios organizadores: o princípio de separação (existem trabalhos de homens e trabalhos de mulheres) e o princípio de hierarquização (um trabalho de homem "vale" mais do que um trabalho de mulher)". Para discussões sobre a divisão sexual do trabalho na Câmara dos Deputados brasileira, ver, por exemplo, Pinheiro (2007) e Luiz Felipe MIGUEL e Fernanda FEITOSA (2009). ${ }^{7}$ Childs e Krook (2006) argumentam que a obra de Kanter (1977) é limitada para tratar da representação política de mulheres, uma vez que: ignora que instituições políticas e corporações possuem dinâmicas de organização e funcionamento diversas; não define as mulheres como minoria política nem considera gênero como categoria de análise relevante, uma vez que enfatiza o status minoritário, independente de seu marcador, e não analisa o papel dos homens, sendo necessário desenvolver uma teoria patriarcal das relações de poder, de forma a apreciar de forma mais adequada as relações entre minoria e maioria.
} 
O termo "massa crítica" foi emprestado da física nuclear, onde ele se refere à quantidade [de energia] necessária para que uma reação em cadeia comece, um ponto de mutação irreversível, o início de uma nova situação ou processo. Por analogia, podese dizer que uma mudança qualitativa acontecerá quando as mulheres ultrapassarem a proporção de 30 por cento em uma organização (DAHLERUP, 2006, p. 2).

Porém, como lembra a autora, os números seriam condição necessária, mas não suficiente: as mulheres constituiriam uma massa crítica apenas potencialmente, uma vez que, além da formação de uma "grande minoria", há questões relativas à ação coletiva e às preferências das legisladoras, que podem minar as possibilidades de uma atuação concertada. Segundo Dahlerup (1993), esses problemas poderiam ser superados a partir do apoio externo de movimentos e organizações feministas, de melhorias na posição socioeconômica das mulheres na sociedade e da garantia de condições de trabalho e influência para as legisladoras. Em outras palavras, a massa crítica depende do tamanho da minoria, mas também da disposição daquelas que a constituem em agir de forma concertada - "atos críticos", ou ações que mudariam a posição da minoria e levariam a mudanças futuras mais profundas (Cf. Joni LOVENDUSKI, 2001) - e da existência de uma estrutura de oportunidades favorável à ação coletiva.

Apesar de ter influenciado grandemente ações relativas ao incremento da representação feminina, tanto em termos acadêmicos quanto políticos, ${ }^{8}$ a teoria da massa crítica foi alvo de questionamentos importantes. Algumas delas se referem não ao argumento de Dahlerup (1993), mas à sua apropriação e uso equivocados por uma "política do otimismo", focada unicamente no incremento do percentual de mulheres nas legislaturas e na crença de que, por si, este fato garantiria a eliminação das desigualdades de gênero sem que houvesse conflitos ou retrocessos (CHILDS; KROOK, 2006, p. 8). Outras críticas importantes dizem respeito à inadequação da analogia com um conceito das ciências exatas; à arbitrariedade da porcentagem sugerida como ponto de corte para se atingir uma "massa crítica" e a impossibilidade de se isolar o efeito do número de representantes eleitas de fenômenos externos ao legislativo.

Dahlerup (2006) indica a necessidade de se incorporarem à análise as características das organizações legislativas e de garantir às mulheres eleitas "condições de trabalho e influência", sendo importante avançar no debate sobre representação política de mulheres para além da entrada nos Parlamentos. Esses elementos chamam a atenção para a necessidade de avaliar, o que significa dizer que as mulheres "fazem a diferença", como lembram Childs e Krook (2006). Essas autoras propõem que a noção de massa crítica seja substituída pela de atores críticos, ou seja, indivíduos (homens e mulheres) que tomam a iniciativa de apresentar propostas e encorajam outros a promover políticas para mulheres, independente do tamanho da minoria feminina. $O$ foco passa a recair sobre legisladoras e legisladores específicas(os) e as ações que implicam representação substantiva.

As autoras apontam que a noção de atores críticos requer que sejam consideradas as seguintes dimensões: os efeitos do aumento da proporção de mulheres no legislativo, considerando possibilidades como o desenvolvimento de estratégias de segregação de mulheres por parte de colegas do sexo masculino e a ampliação da diversidade de

\footnotetext{
${ }^{8}$ Resolução do Conselho Econômico e Social das Nações Unidas publicada em 1990 recomendou que, até 1995, 30\% dos postos de tomada de decisão fossem ocupados por mulheres e que esse número fosse elevado para $50 \%$ até 2000 . Diante dos pequenos avanços no tocante a essas metas, a Declaração e Plataforma de Ação da IV CONFERÊNCIA MUNDIAL SOBRE MULHER estabelece que os países signatários devem "adotar medidas concretas para criar uma massa crítica de mulheres dirigentes, executivas e administradoras em postos estratégicos de tomada de decisões" (VIOTTI, 2006).
} 
interesses por parte das legisladoras, que poderia levar a uma representação de interesses difusos e não apenas de "interesses de mulheres"; as características das organizações legislativas e do processo legislativo, ou o modo como regras formais e informais distribuem poder entre homens e mulheres, além de aspectos como filiação e ideologia partidárias; identidades e interesses de legisladoras e legisladores, considerando o entrelaçamento de aspectos como classe, raça e geração, por exemplo, e o risco do discurso da diferença, relacionado à essencialização de uma "identidade feminina" que pode atuar como justificativa à segregação das mulheres, bem como a existência de definições feministas e não feministas das "questões de mulheres", de forma a ampliar o escopo de temas que afetam a vida cotidiana de mulheres.

Considerando os aspectos apontados por Dahlerup $(1993,2006)$ e Childs e Krook (2006) relacionados às condições que levariam à emergência de atos críticos, destacamse, no escopo desse artigo, especificamente: a) "condições de trabalho e influência para as legisladoras" ou o "modo como regras formais e informais distribuem poder entre homens e mulheres" e b) questões relacionadas à ação coletiva, à coordenação da ação, que implicam um processo de construção de identidade coletiva entre as legisladoras. O primeiro desses aspectos demanda uma análise da organização do processo decisório na Câmara dos Deputados, de forma a identificar princípios que orientam a distribuição de recursos políticos e, por conseguinte, definem as possibilidades de influenciar o processo decisório (ou de desenvolver atos críticos). A segunda dimensão remete à discussão sobre as possibilidades de que as legisladoras atuem coletivamente, suspendendo, portanto, lealdades partidárias, regionais e outras, em nome da representação de uma perspectiva social (YOUNG, 2002) relacionada ao gênero. O foco nesses aspectos permite avaliar se e como atos críticos são possíveis em contextos em que as regras do jogo limitam os recursos procedimentais a minorias políticas, como aquela representada pelas legisladoras na Câmara dos Deputados, levando em conta, também, que outros fatores atravessam as perspectivas representadas.

Assim, um primeiro passo para avaliar a representação de mulheres é definir o que se entende por minoria e analisar os recursos disponíveis para sua atuação. Além das contribuições de Dahlerup $(1993,2006)$ a respeito do conceito de minoria, apresentadas anteriormente, é importante incorporar as definições desenvolvidas por Sarah A. Binder (1997), uma vez que a autora enfatiza a distribuição de recursos políticos para grupos minoritários no contexto do poder Legislativo, a partir do conceito de direitos de minorias.

Binder (1997) afirma que minorias legislativas podem ser classificadas em partidárias e políticas. Uma minoria partidária é caracterizada pelo pertencimento a um partido minoritário. Já uma minoria política é minoria de qualquer tipo e tamanho, podendo ser definida por características adscritas, como gênero e raça, ou pertencimento religioso, por exemplo (BINDER, 1997). Uma minoria política não necessariamente se caracteriza como minoria partidária, podendo estar dispersa em vários partidos, como no caso das deputadas brasileiras, o que pode gerar desafios para a ação coletiva e mesmo para o desenvolvimento de uma identidade coletiva. Quanto aos direitos de minorias, a literatura enfatiza as possibilidades de atuação de partidos minoritários em um contexto majoritário, avaliando em que medida minorias partidárias podem influenciar o processo decisório. Nesse sentido, direitos de minorias podem ser definidos como

vantagens procedimentais protegidas de mudanças arbitrárias que permitem que membros do partido minoritário emendem, debatam ou obstruam a agenda maioria. Uma vantagem procedimental confere a um indivíduo ou grupo acesso preferencial ao processo legislativo em estágio específico do jogo (BINDER, 1997, p. 21). 
Apesar de se referirem apenas a minorias partidárias, essas vantagens foram configuradas originalmente no caso estudado pela autora, as Casas legislativas estadunidenses, como direitos de minorias políticas. Segundo Binder (1997), direitos de minorias políticas se aproximam de direitos de minorias partidárias na medida em que ambos podem se traduzir como direitos garantidos a parlamentares individuais. Entretanto, é relevante ressaltar que, historicamente, direitos conferidos a minorias passaram a privilegiar as minorias partidárias, o que indica que os partidos ganharam relevância como mediadores na distribuição de recursos legislativos e, por conseguinte, critérios de alocação de recursos assumiram caráter partidário.

Ademais, a discussão sobre direitos de minorias chama atenção para o fato de que, se, em tese, a representatividade de uma legislatura se assenta num compromisso com a participação igualitária de seus membros, a prática revela que os direitos das minorias apresentam um caráter contingente, uma vez que são condicionados pela configuração das forças partidárias (BINDER, 1997, p. 2). Isso significa que a caracterização das deputadas federais brasileiras como minoria política deve considerar, necessariamente, o papel dos partidos na Câmara dos Deputados e como a dimensão de gênero atravessa tais organizações.

Com relação ao papel dos partidos políticos nesta Casa legislativa, a produção da Ciência Política nacional identifica que esses são um dos pilares de sustentação do presidencialismo de coalizão, na medida em que o processo decisório no Legislativo está assentado em bases partidárias, vide a atuação do Colégio de Líderes e seu papel na definição da agenda legislativa e a adoção do critério da proporcionalidade partidária para a distribuição de recursos como vagas em comissões e na Mesa Diretora (Argelina FIGUEIREDO; Fernando LIMONGI, 1998; SANTOS, 2002). Nesse sentido, é importante considerar em que medida os partidos adotam critérios generificados na alocação dos recursos mencionados, produzindo e reproduzindo, portanto, a desigualdade de gênero no Legislativo.

Em pesquisa sobre gênero e partidos políticos na América Latina, Vivián ROZA, Beatriz LLANOS e Gisela GARZÓN DE LA ROZA (2010) verificaram a existência de inúmeras barreiras à representação de mulheres, tais como: o caráter piramidal da participação feminina, que se caracteriza por seus altos percentuais na base, combinado com escassos números nas elites partidárias; a inexistência de referência à equidade de gênero e temas correlatos em documentos de metade dos partidos investigados; a pequena oferta de capacitações e cursos de formação de lideranças femininas; a inexistência de princípios paritários como critérios para o financiamento de campanhas e a ausência de reserva de vagas para mulheres em órgãos decisórios dos partidos.

No Brasil, os trabalhos de Araújo (2005), Sacchett (2012), Irlys BARREIRA e Danyelle Nilin GONÇALVES (2012) e Santos, Paula e Seabra (2012) avaliam como instituições, atores e estratégias partidárias são centrais para a manutenção da desigualdade de gênero na política institucional. Diante desse quadro, é razoável supor que os partidos políticos brasileiros são instituições generificadas e que os recursos por esses alocados obedecem, ainda que tacitamente, a critérios baseados em gênero.

Finalmente, outro elemento-chave no que toca à definição de minorias políticas diz respeito à construção de uma identidade coletiva, o que traz à baila questões relativas à coordenação da ação. Nesse sentido, considero que a existência de mecanismos como comissões de mulheres/gênero e de bancadas femininas pode fomentar não apenas a produção de políticas que promovam justiça de gênero, mas também estimular a criação de 
redes de solidariedade e troca de informações, formação de lideranças e advocacy. ${ }^{9}$ Tais estruturas podem, pois, permitir o desenvolvimento de estratégias de acomodação de interesses partidários divergentes e fomentar a construção de uma agenda comum às legisladoras, o que permitiria identificá-las como um grupo ou como uma minoria que se organiza a partir de princípios que ultrapassam o pertencimento partidário - assim, um importante indicador de que as legisladoras constituem uma minoria política e a existência de bancadas femininas ou de comissões relacionadas a "questões de gênero" ou "interesses de mulheres".

A formação da bancada feminina na Câmara dos Deputados se deu durante a Assembleia Constituinte eleita em 1986 como parte do processo de transição democrática. Sua emergência ocorreu, portanto, em uma conjuntura crítica (Fiona MACAULAY, 2005) que envolvia, além do momento constituinte, um incremento no número de deputadas eleitas, que saltou de 8 (oito) na legislatura anterior para 26 (29, se consideradas as suplentes que assumem mandato durante a legislatura) e uma intensa relação com movimentos sociais mediada pelo Conselho Nacional da Condição da Mulher, criado em 1985 e responsável por uma ampla campanha de mobilização que tinha como objetivo fazer com que a Constituição garantisse direitos das mulheres.

Trata-se de uma bancada multipartidária composta por deputadas federais. Como indica Sonia PALMIERI (201 1), tal configuração impõe alguns desafios à sua atuação como um ator coletivo, relacionada à existência de outras lealdades, mais especificamente o pertencimento partidário e o estado de origem das legisladoras. Dessa forma, uma função importante da bancada feminina é justamente forjar uma identidade coletiva que permita a ação concertada de legisladoras com pertencimentos partidários, eleitorado e trajetórias tão distintas. Adriana OLIVEIRA (2012) afirma que esse desafio está presente desde o momento da emergência da bancada e essa heterogeneidade influenciou a agenda avançada pela bancada feminina (Daniela REZENDE; Ana Carolina Freitas Lima OGANDO, 2016)..$^{10}$ Assim, a existência da bancada feminina e os recursos disponíveis para que essa possa influenciar o processo decisório na Câmara dos Deputados são elementos centrais para a avaliação dos desafios à atuação das legisladoras, esforço que será desenvolvido na próxima seção.

\section{Metodologia, dados e discussão}

Considerando a literatura apresentada, a estratégia metodológica adotada partiu da identificação de recursos políticos centrais no que tocava ao processo decisório na Câmara dos Deputados, a partir da análise de seu Regimento Interno. Essa leitura foi orientada pela análise de Gary COX e Matthew D. McCUBBINS (1993; 2005), que identificam que a presidência da Mesa Diretora e as presidências de comissões permanentes são recursos importantes, na medida em que garantem a seus membros prerrogativas associadas que podem afetar o processo de tomada de decisões. Além desses, destaca-se, ainda, a ałuação da bancada feminina, responsável por promover a coordenação de legisladoras dispersas em distintos partidos e de forjar uma identidade coletiva, podendo, também, mitigar os constrangimentos relacionados a seu status minoritário. À identificação de tais recursos seguiu-se a explicitação das regras que orientam a sua distribuição, incluindo, quando possível, a referência a normas informais.

A análise documental foi sucedida por análise descritiva ou exploratória dos dados relativos à alocação de recursos entre legisladoras e legisladores, com o objetivo de

\footnotetext{
9 Como indicam os trabalhos de Kristin KANTHAK e George KRAUSE (2012) e Jennifer PISCOPO (2014).

${ }^{10}$ Uma análise detalhada do perfil das legisladoras foge ao escopo deste artigo. Entretanto, essa heterogeneidade pode ser identificada a partir do estudo desenvolvido por Pinheiro (2007).
} 
apresentar um panorama da distribuição de recursos políticos na Câmara dos Deputados. Na seção seguinte, esses dados são apresentados e discutidos, considerando o quadro analítico construído na seção anterior.

A análise do Regimento Interno da Câmara dos Deputados permite observar que o critério fundamental para distribuição de postos críticos é a proporcionalidade partidária, que assegura que a alocação de recursos espelhe a distribuição de cadeiras entre os partidos representados na Casa. Tal critério, que orienta a composição de todos os colegiados da Casa, é fixado constitucionalmente.

Segundo Ingvar MATTSON e Kaare STRÖM (1995), essa regra imprime um caráter mais consensual a esses órgãos, além de permitir alguma margem de atuação às minorias partidárias. A diversidade das e dos parlamentares em termos de pertencimento partidário também pode contribuir para que distintos interesses sejam considerados no processo deliberativo. Entretanto, é preciso observar que prerrogativas que garantem direitos a minorias partidárias nem sempre implicam direitos de minorias políticas, uma vez que essas podem estar distribuídas em diversos partidos e serem postergadas quando da distribuição de recursos políticos por lideranças partidárias. Ademais, essa questão remete ao argumento da massa crítica e à necessidade de eleger mais mulheres, uma vez que, para alocar legisladoras em tais posições, líderes partidários devem contar com um percentual mínimo de deputadas nas bancadas de seus partidos, o que ainda é um desafio no contexto brasileiro.

A partir do exposto, a seguir, serão discutidos os recursos identificados no Regimento Interno, o que inclui a descrição de suas prerrogativas e a avaliação de sua distribuição entre legisladoras e legisladores.

\section{Mesa Diretora}

A Mesa Diretora é o colegiado responsável pela direção dos trabalhos legislativos e administrativos da Câmara dos Deputados e é composta por seis membros: presidente, vice-presidente e quatro secretários. Dentre suas prerrogativas, destacam-se a emissão de parecer a respeito de alterações no Regimento Interno, a apreciação e encaminhamento de pedidos de informação a Ministros de Estado e a distribuição de vagas em comissões entre partidos e/ou blocos partidários (BRASIL, 201 1). A composição da Mesa deve obedecer, quando possível, ao princípio da proporcionalidade partidária.

Considerando as prerrogativas dos diversos cargos que a compõem, a presidência possui elevada capacidade de afetar o processo decisório, porque concentra importantes poderes, como conceder a palavra a parlamentares e controlar o uso do tempo de fala, definir a agenda mensal da Casa e a Ordem do Dia, ou seja, selecionar que proposições serão discutidas e votadas nas seções legislativas. Ademais, esse cargo é o terceiro na linha sucessória da Presidência da República. Vê-se, pois, que à/ao ocupante desse cargo estão asseguradas amplas possibilidades de influenciar o processo decisório, cabendo, inclusive, definir o que deve ser discutido e votado e quando.

Ao analisar a distribuição de cargos da Mesa Diretora entre legisladoras e legisladores, fica explícito o viés de gênero: até o ano de 2014, nenhuma mulher ocupou a presidência da Casa. Quanto aos demais cargos, entre 1981 e 2007, quatro deputadas assumiram cargos de suplência na Secretaria da Mesa Diretora ${ }^{11}$ e apenas em 2011 uma mulher foi eleita vice-presidente. ${ }^{12}$ Diante desse quadro, a deputada Luiza Erundina apresentou, em 2006, uma Proposta de Emenda Constitucional (PEC590/2006) que prevê a

"Ver Agência Câmara (2007)

12 Ver Agência Câmara (2011). 
reserva de ao menos uma vaga para as legisladoras nas Mesas Diretoras da Câmara, do Senado e das comissões. Tal proposta foi aprovada nas análises de mérito realizadas pelas Comissões Legislativas, mas aguardou três anos para ser incluída na Ordem do Dia, ação que compõe uma das prerrogativas da presidência da Câmara. Em março de 2015, a PEC foi aprovada na Câmara dos Deputados e encaminhada ao Senado, ${ }^{13}$ onde aguarda, desde abril de 2016, para ir à votação em plenário. O longo processo até a aprovação da PEC 590/2006 na Câmara dos Deputados reforça o argumento de que a presidência da Mesa Diretora é central no que tange à organização do processo decisório e à importância de que seja assegurada às legisladoras representação nessa instância. Além disso, a ausência de mulheres da Mesa também se deve a dinâmicas partidárias de alocação de recursos legislativos, uma vez que o critério adotado é a proporcionalidade partidária. Tal fato, somado à escassa presença de deputadas e, mesmo, sua ausência em algumas bancadas partidárias, agrava a desigualdade de gênero no que toca à Mesa Diretora.

\section{Comissões permanentes}

As comissões legislativas e, em especial, as comissões permanentes, cujas jurisdições são definidas pelo Regimento Interno, são instâncias associadas ao desenvolvimento e especialização do poder legislativo, particularmente importantes para a atuação de minorias, devido à sua escala e ao critério de proporcionalidade partidária adotado na sua composição e distribuição de suas presidências.

A participação em comissões também pode promover a especialização dos/as parlamentares em determinados temas, definidos pelas jurisdições comissionais, além de informar o processo decisório, por meio da produção de pareceres ou informes, realização de audiências públicas, coleta de informações junto à administração pública e sabatina de autoridades. Ademais, pode garantir a seus membros grande capacidade de influenciar o processo decisório, a depender de suas prerrogativas e saliência. Por fim, destaca-se a função de fiscalização do Executivo atribuída a esses órgãos, que pode ser estratégica para minorias e garantir importantes recursos, mesmo em contextos em que o poder legislativo das comissões são limitados. Nesse sentido, o pertencimento a determinadas comissões legislativas pode se traduzir em importantes recursos políticos (MAATSON; STRÖM, 1995).

Santos (2002) e Gustavo MÜLLER e Fernando MEIRELES (2014) verificaram que o fator que explica de forma mais adequada a distribuição de vagas em comissões é a especialização de parlamentares, definida a partir da área formação universitária e sua relação com a jurisdição das comissões. É importante considerar que o recrutamento para comissões legislativas se baseia em critérios que variam segundo sua jurisdição, a saliência das mesmas para os distintos partidos e as preferências e recursos disponíveis às/aos legisladoras/es. Entretanto, até o presente, poucas análises acerca da integração das comissões legislativas no Brasil consideraram que gênero pode ser uma dimensão relevante na distribuição de recursos políticos, o que explicita seu caráter gender-blind.$^{14}$ Tal omissão impede que se construa um quadro mais completo do processo de alocação de recursos políticos na Câmara dos Deputados e da desigualdade de gênero no legislativo.

Na Câmara dos Deputados, as vagas nas comissões permanentes são alocadas segundo o princípio da proporcionalidade e os líderes partidários são responsáveis pela alocação de parlamentares nas vagas disponíveis para o partido. Considerando a distribuição de vagas em comissões permanentes no período entre 1995-2010 - disponível

${ }^{13}$ No Senado, a PEC recebeu o número de PEC 38/2015.

${ }^{14}$ Duas exceções são Rezende (2015) e Pedro NEIVA e Ogando (2010). 
na tabela 1, verifica-se que as legisladoras estão sobre-representadas em seis comissões: Defesa do Consumidor, Desenvolvimento Urbano, Direitos Humanos e Minorias, Educação, Legislação Participativa, Segurança Pública e Combate ao Crime Organizado e Seguridade Social e Família. Nas demais comissões, o percentual de mulheres é inferior ao percentual médio de legisladoras na Câmara dos Deputados no período analisado (7,5\%).

Tabela 1 - Percentual médio de deputadas e deputados em comissões permanentes da Câmara dos Deputados, 1995-2010

\begin{tabular}{|c|c|c|c|}
\hline \multirow[t]{2}{*}{ Comissito } & \multicolumn{2}{|c|}{ Sexo } & \multirow[t]{2}{*}{ Total } \\
\hline & $\mathbf{F}$ & w & \\
\hline \multirow{2}{*}{ Amazsnia, integraçso Nacional e de Desarvolvimento Rlogional } & 31 & 204 & 235 \\
\hline & $(13,19)$ & $\{86,81\}$ & \\
\hline \multirow{2}{*}{ Agrioultura, Peousris, Abastecimento e Dessemrohomento Rural } & 26 & 565 & 581 \\
\hline & $\langle 4,48\rangle$ & $(96,52\rangle$ & \\
\hline \multirow{2}{*}{ Cienda, Tecnologis e Telecomuricasoes } & 20 & 599 & 619 \\
\hline & $\langle 3.23\rangle$ & $(96,77\rangle$ & \\
\hline \multirow{2}{*}{ 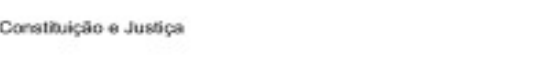 } & 32 & 704 & 735 \\
\hline & $(4,35)$ & $(96,65)$ & \\
\hline \multirow{2}{*}{ Desosa do Consumidor } & 34 & 284 & 318 \\
\hline & $(10,68)$ & $\{89,31\}$ & \\
\hline \multirow{2}{*}{ Deservolvimento Urtano } & 35 & 272 & 307 \\
\hline & $\{11,4\}$ & (68,6) & \\
\hline \multirow{2}{*}{ Direitos Humancos o Minorias } & 40 & 247 & 287 \\
\hline & (13.94) & {$[86,06\rangle$} & \\
\hline \multirow{2}{*}{ Economia, Indúseria e Camaircio } & 18 & 303 & 321 \\
\hline & $(4,59)$ & $(96,41)$ & \\
\hline \multirow{2}{*}{ Ecuosscaģăo e Cuttura } & 69 & 276 & 345 \\
\hline & (20) & (80) & \\
\hline \multirow{2}{*}{ Fhanças e Tributaçso } & 16 & 468 & 464 \\
\hline & 〈3.31\} & $(96,69\rangle$ & \\
\hline \multirow{2}{*}{ Fiscalicasâo Finsceira e Controle } & 10 & 349 & 359 \\
\hline & (2.79\}) & $(97,21\rangle$ & \\
\hline \multirow{2}{*}{ Legisiaşăo Partcipativa } & 18 & 101 & 119 \\
\hline & $(15,13)$ & $[84,87\rangle]$ & \\
\hline \multirow{2}{*}{ Msio Ambiente e Desemvotrimento Sustantasud } & 4 & 46 & 50 \\
\hline & (8) & $\{92\}$ & \\
\hline \multirow{2}{*}{ Mnas e Energia } & 6 & 312 & 318 \\
\hline & $\{1,09\}$ & $(96,11)$ & \\
\hline \multirow{2}{*}{ Relapdes Exteriores ef Detess Nacional } & 31 & 516 & 547 \\
\hline & $\langle 5,67\rangle$ & $(94,33)$ & \\
\hline \multirow{2}{*}{ Seguranga Pública e Combate as Crime Organizado } & 14 & 97 & 111 \\
\hline & (12,61) & $(87,39)$ & \\
\hline \multirow{2}{*}{ Seguridade Social o Famlia } & 110 & 412 & 522 \\
\hline & $(21,07)$ & $(78,93)$ & \\
\hline \multirow{2}{*}{ Trabaho, de Administracaso e Servico Púbaco } & 22 & 317 & 399 \\
\hline & $\langle 6,49\}$ & $(90,51)$ & \\
\hline \multirow{2}{*}{ Turismo e Despocto } & 4 & 69 & 73 \\
\hline & $(5,48)$ & $(94,52)$ & \\
\hline \multirow[t]{2}{*}{ Viaçือ e Transpertes } & 19 & 480 & 499 \\
\hline & $\langle 3,81\rangle$ & $(96,19)$ & \\
\hline \multirow{2}{*}{ Total } & 559 & 6.611 & 7.170 \\
\hline & (7,8) & $(92.2)$ & \\
\hline
\end{tabular}

Fonte: Elaboração própria a partir de dados cedidos pela Câmara dos Deputados.

Obs: Ao longo do período analisado, as jurisdições comissionais sofreram alterações. Optei por apresentar os dados de forma agregada para comissões com áreas de atuação sobrepostas ou semelhantes. 
Considerando o desenho do sistema comissional e as prerrogativas associadas a cada um desses órgãos, destacam-se as Comissões de Constituição e Justiça e Finanças e Tributação, responsáveis por emitir parecer sobre todas as proposições tramitadas na Câmara do Deputados e que detêm o poder de impedir ou interromper sua tramitação caso sejam consideradas inconstitucionais ou inconformes com relação ao Orçamento (SANTOS, 2002). Observando a composição de tais comissões, verifica-se que o percentual de mulheres não chega a $5 \%$.

Pode-se argumentar que, apesar dos baixos percentuais, as legisladoras estão representadas em todas as comissões, o que poderia assegurar a transversalidade de gênero nas deliberações que tomam lugar nessas instâncias. Entretanto, avaliando que as mulheres estão distribuídas em diversos partidos políticos, há grande possibilidade de que a representação da perspectiva de gênero fique subordinada ao pertencimento partidário, hipótese que deve ser avaliada a partir da análise do trabalho desenvolvido nessas instâncias.

Em abril de 2016, foi criada a Comissão de Defesa dos Direitos da Mulher, alvo de intensos debates na Câmara dos Deputados. ${ }^{15}$ Essa nova comissão tem como jurisdição questões relativas à violência, trabalho e saúde (excluídas questões relativas a direitos sexuais e reprodutivos) e discriminação racial. Antes de sua criação, temas relativos às mulheres eram tratados pela Comissão de Seguridade Social e Família e questões relativas a grupos minoritários são de responsabilidade da Comissão de Direitos Humanos e Minorias, comissões que contam com grande número de legisladoras.

Apesar da concentração de legisladoras nessas duas comissões, Jennifer Piscopo (2014, p. 12) afirma que a inexistência de uma comissão específica voltada a questões de gênero aumenta os problemas de ação coletiva e requer que as legisladoras invistam mais tempo identificando e acompanhando propostas dispersas em várias comissões. No entanto, o caso brasileiro indica que a própria comissão pode ser alvo de disputas que se relacionam à distribuição de recursos (cargos como presidências de comissões) e também à possibilidade de controle da agenda legislativa, como se vê no caso dos direitos sexuais e reprodutivos. Ademais, a própria bancada feminina se dividiu com relação à criação da Comissão de Defesa dos Direitos da Mulher, fato que trouxe à tona lealdades partidárias e religiosas. Finalmente, como indicam Roseanna HEATH, Leslie SHWINDT-BAYER e Michelle TAYLOR-ROBINSON (2005), foi verificado que a existência de comissões específicas de mulheres ou de gênero pode implicar segregação das legisladoras e dificultar seu acesso a outras comissões.

Pode-se argumentar que os problemas de coordenação mencionados acima podem ser mitigados pela existência da Bancada feminina, que, em 2013, assumiu o nome de Secretaria da Mulher. Como será discutido abaixo, uma das atribuições da bancada é justamente acompanhar a tramitação de propostas relativas às mulheres, além de fomentar a atuação coordenada a respeito de temas comuns às legisladoras.

Com relação às presidências de comissões permanentes, estas são compostas por três membros, um presidente e três vice-presidentes. Nesses colegiados, assim como na Mesa Diretora, destacam-se os poderes atribuídos à presidência, como convocar e definir as pautas das reuniões e designar relatores para as proposições submetidas à sua apreciação. Quanto à seleção das presidências das mesmas, também é adotado o critério da proporcionalidade partidária. O método de seleção de presidentes definido regimentalmente é a eleição pelos membros da comissão. Entretanto, é necessário destacar que o Regimento Interno não detalha como seriam distribuídas as presidências de comissões entre os partidos, o que indica que essa distribuição seja fruto de acordos.

Carlos PEREIRA e Bernardo MUELLER (2000) afirmam que os/as presidentes de comissões são selecionados/as por líderes partidários e que o bloco partidário majoritário controla as ${ }^{15}$ Ver UOL Notícias, 2016. 
presidências das comissões mais importantes. Fabiano Santos e Lúcio RENNÓ (2004) verificaram que o número de mandatos legislativos prévios é um critério relevante para a seleção dos/as presidentes de comissões na Câmara dos Deputados. Ademais, ali prevalece a regra informal de que o tamanho dos partidos define a ordem de escolha das presidências de comissões. ${ }^{16}$

Esses procedimentos informais reafirmam a centralização do processo decisório nas lideranças partidárias e o papel meramente formal das eleições das autoridades no âmbito das comissões, o que pode levar a uma restrição dos direitos de minorias políticas, uma vez que, como dito anteriormente, tais regras podem obscurecer critérios ilegítimos de distribuição de recursos (HEATH, TAYLOR-ROBINSON, SCHWINDT-BAYER, 2005; Diana Z. O'BRIEN, 2012).

Avaliando a distribuição de presidências de comissões entre legisladoras e legisladores no período entre 1995-2010 (tabela 2), verifica-se que há comissões que nunca foram presididas por mulheres, como as de Agricultura, Constituição e Justiça, Desenvolvimento Econômico, Fiscalização Financeira e Controle, Meio Ambiente, Minas e Energia, Trabalho, Administração e Serviço Público e Viação e Transportes. A Comissão de Educação e Cultura destaca-se como a Comissão que mais vezes foi presidida por legisladoras (quatro mandatos), seguida das Comissões de Amazônia e Integração, Defesa do Consumidor e Seguridade Social e Família (três mandatos).

Tabela 2 - Presidências de comissões permanentes da Câmara dos Deputados ocupadas por deputadas, 1995-2010

\begin{tabular}{|c|c|}
\hline Comissbo & Nümero ateolisto \\
\hline 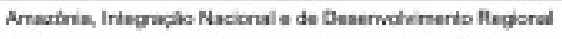 & 3 \\
\hline 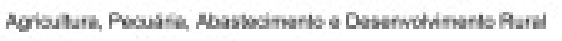 & 0 \\
\hline Cetrais. Teonchogis o Telecorrunicagles & 0 \\
\hline Conativiclo e Jabipa & 0 \\
\hline Delosa do Consumidor & 3 \\
\hline Desenvoduments Utarno & 2 \\
\hline Devides Humania e Mnorias & 2 \\
\hline Economia Indistis o Combins & 0 \\
\hline Edveagla e Cutura & 4 \\
\hline Francas e Trouspabo & 1 \\
\hline Feralizaglo Fuscelas a Contrite & 0 \\
\hline Legelagso Parsopativa & .. \\
\hline 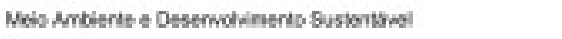 & 0 \\
\hline Winas a Erarga & a \\
\hline 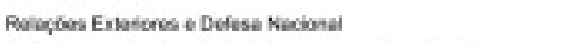 & 1 \\
\hline 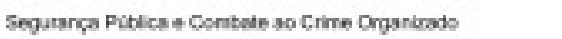 & 1 \\
\hline Segurictude Social e farnia & $\mathbf{3}$ \\
\hline Tratedha de Mdrinietraglo e Servico Putbso & 0 \\
\hline Turiemo e Deeporto & 1 \\
\hline Vapase Trierspones & 0 \\
\hline
\end{tabular}

Fonte: Elaboração própria a partir de dados cedidos pela Câmara dos Deputados.

Obs. 1: Ao longo do período analisado, as jurisdições comissionais sofreram alterações. Optei por apresentar os dados de forma agregada para comissões com áreas de atuação sobrepostas ou semelhantes. Obs. 2: No banco de dados consultado não constam informações relativas a comissão de Legislação Participativa.

${ }^{16}$ Esse processo foi explicitado a partir das polêmicas envolvendo a presidência da Comissão de Direitos Humanos e Minorias, no ano de 2013. Cf. UOL Notícias, 18/02/2014. 
Interessante notar que, na ausência de uma comissão de "assuntos de mulheres", a participação das legisladoras como presidentes de comissão se concentra nas comissões cujas jurisdições incluem temas relativos ao cuidado: as comissões de Seguridade Social e Família, Educação e Cultura e Direitos Humanos e Minorias compreendem a quase metade das vezes em que as legisladoras presidiram comissões ( 9 em 21 ou 42,85\%).

Esse quadro, associado ao anteriormente apresentado sobre a distribuição de vagas em comissões legislativas, explicita a distribuição desigual de recursos entre deputadas e deputados, indicando também a existência de uma espécie de divisão sexual do trabalho legislativo em que legisladoras se ocupam de temas relativos ao cuidado, reproduzindo os papéis tradicionalmente associados às mulheres, enquanto os legisladores se dedicam a temas mais prestigiosos, como Orçamento, por exemplo. Uma análise mais acurada desse quadro deveria considerar, no entanto, a interação entre as variáveis identificadas pela literatura como relevantes no que toca ao recrutamento para as comissões, como especialização e número de mandatos anteriores, por exemplo, com a dimensão de gênero, de forma a identificar tanto mecanismos que operam para a exclusão das mulheres de alguns desses colegiados quanto estratégias de resistência por parte das legisladoras.

\section{Bancada feminina}

A Bancada Feminina foi criada no contexto da Assembleia Constituinte em 1986, quando ficou conhecida como "Bancada do Batom". Nesse período, foi composta por 26 legisladoras que atuaram além das linhas partidárias e garantiram importantes conquistas com relação aos direitos das mulheres (Céli Regina Jardim PINTO, 2003). Entretanto, a Bancada Feminina foi institucionalizada apenas em 2013 (PISCOPO, 2014; Candyce da Cruz ROCHA, 2015), a partir da criação da Secretaria da Mulher, órgão que passou a agregar a Procuradoria da Mulher, instância responsável pelo fomento da participação das legisladoras nos diversos órgãos da Câmara dos Deputados, e a Coordenadoria de Direitos da da Mulher (Bancada Feminina). ${ }^{17}$

Essa iniciativa é um marco não apenas com relação à representação de mulheres, mas também com relação ao conceito de minorias políticas, uma vez que à Secretaria da Mulher foram assegurados poderes até então disponíveis apenas para lideranças partidárias, como assento no Colégio de Líderes, com direito a voz e voto, direito de fazer uso do tempo disponível às lideranças partidárias nas comunicações em Plenário e garantia de infraestrutura, como equipe técnica, para acompanhamento das proposições de interesse (ROCHA, 2015).

Do ponto de vista da discussão sobre minorias políticas, isso significa que essas foram equiparadas às minorias partidárias, o que indica o reconhecimento de que a alocação de recursos políticos deve obedecer a outras lógicas além da partidária. Esse reconhecimento fortalece o papel da Secretaria da Mulher no que toca à formação de uma identidade coletiva que ultrapassa pertencimentos partidários, fomentando a ação coletiva e aumentando as possibilidades de que iniciativas relacionadas à garantia dos direitos das mulheres possam avançar na Câmara dos Deputados.

Entretanto, alguns obstáculos ainda se apresentam à atuação efetiva da Secretaria da Mulher, relacionados à prevalência de outras lealdades (partidárias, regionais e religiosas, por exemplo), o que é reforçado pelo pequeno número de mulheres eleitas. A inexistência de regras formais que definam a organização da Secretaria da Mulher, especificamente com relação à eleição de autoridades, pode implicar a introdução de

${ }^{17}$ Informações disponíveis em: http://www2.camara.leg.br/a-camara/secretaria-da-mulher/o-que-e-a-secretariada-mulher.

1212 Estudos Feministas, Florianópolis, 25(3): 1199-1218, setembro-dezembro/2017 
critérios outros que não a identidade coletiva de mulheres, como o pertencimento partidário. Essas alterações, introduzidas na 55 legislatura (2015-2019), podem dificultar a ação coletiva e a criação de rede de solidariedade que ultrapasse lealdades partidárias, enfraquecendo a atuação coordenada das legisladoras. Um dos desafios que se impõe é, portanto, que a ação coordenada das legisladoras possa fortalecer iniciativas voltadas à eleição de mais legisladoras, além de iniciativas que garantam uma distribuição de recursos mais equitativa entre homens e mulheres na Câmara.

Ademais, como indicam Rezende e Ogando (2016), a análise da atuação da bancada feminina deve considerar, além de sua estrutura e prerrogativas, a relação com movimentos sociais, sua agenda, os recursos de fato disponíveis para órgão, o perfil das legisladoras e as dinâmicas de construção de uma identidade coletiva.

\section{Considerações finais}

Este artigo discutiu alguns dos desafios à representação política de mulheres na Câmara dos Deputados. No Brasil, a despeito da adoção das cotas eleitorais como importante estratégia de inclusão de mulheres e do debate acerca dos mecanismos que poderiam ampliar o percentual de mulheres em cargos eletivos, pouco tem sido discutido sobre as possibilidades e constrangimentos associados à atuação daquelas que conseguem se eleger. Isso indica que à demanda pela eleição de mais mulheres deve ser agregada a discussão sobre as regras e procedimentos que regulam sua atuação, uma vez que essas podem limitá-la (ou, mesmo, anulá-la) ou torná-la mais efetiva do ponto de vista da representação de mulheres.

Essa abordagem parte da revisão da teoria da massa crítica e do argumento de que o foco no percentual de mulheres eleitas pode minimizar a importância da análise do processo decisório para a inclusão de perspectivas de gênero nas decisões políticas. Assim, é importante avaliar não apenas os números relativos que configuram maioria e minoria, mas os recursos disponíveis a esses grupos, que podem potencializar sua influência nos processos deliberativos e mitigar a desigualdade de gênero na formulação de políticas públicas.

Tais recursos foram identificados a partir da análise do Regimento Interno da Câmara dos Deputados. Verificou-se que o documento assegura recursos importantes a minorias partidárias a partir da adoção da proporcionalidade partidária como critério para alocação de recursos, como assentos na Mesa Diretora e presidências de comissões legislativas. Entretanto, não há garantia de recursos a minorias políticas ou grupos organizados a partir de pertencimentos que ultrapassam os vínculos partidários, como é o caso das deputadas.

Avaliando a distribuição desses recursos entre legisladoras e legisladores, pode-se constatar que essa ocorre de forma desigual: nenhuma legisladora ocupou a presidência da Mesa Diretora; as legisladoras estão sub-representadas em comissões importantes, como as de Constituição e Justiça e Finanças e Tributação; pouquíssimas legisladoras presidiram comissões permanentes no período analisado.

Apesar disso, destaca-se a criação da Secretaria da Mulher, que garantiu à Bancada Feminina prerrogativas até então asseguradas apenas às minorias partidárias, além de fomentar o desenvolvimento de uma identidade coletiva e da construção de uma agenda que ultrapasse vínculos partidários. No entanto, é preciso atentar para a institucionalização dos procedimentos que organizam a Secretaria da Mulher, de forma a impedir que critérios outros, como o pertencimento partidário, minem a capacidade de auto-organização e a atuação conjunta das legisladoras.

A discussão apresentada chama atenção para o fato de que o critério que rege a distribuição de recursos políticos na Câmara dos Deputados, a proporcionalidade partidária, 
pode terminar por reforçar a desigualdade de gênero, uma vez que desconsidera que os partidos são instituições generificadas. Nesse sentido, seria importante avaliar em que medida as lógicas partidárias reforçam ou mitigam a desigualdade na distribuição de recursos políticos entre deputados e deputadas. Tal análise deve considerar não apenas as regras formais que organizam o processo decisório, abordagem adotada no presente artigo, mas também regras e redes informais e como estas se estruturam a partir de critérios generificados.

Além disso, seria relevante analisar quais os efeitos do quadro aqui apresentado na formação da agenda e na produção legislativas. Em outras palavras, é necessário avançar no sentido de avaliar como a desigualdade na distribuição de vagas em comissões, presidências de comissões e na Mesa Diretora impacta a emergência de temas relacionados a gênero e à produção de leis e políticas públicas para mulheres. Tal abordagem deve considerar, além das regras de organização do processo decisório, o perfil das legisladoras e as estratégias por essas adotadas na Câmara dos Deputados. Apesar de fugir ao escopo deste artigo, essa etapa pode ser entendida como seu desdobramento lógico.

Finalmente, é importante destacar que permanece o desafio de eleger mais mulheres, mas não se pode esquecer que esse se articula à necessidade de garantir que às mulheres já eleitas sejam assegurados recursos políticos que potencializem mudanças em direção à maior representação de mulheres, garantindo sua presença em todas as instâncias da política institucional.

\section{Referências}

ÁLVARES, Maria Luiza Miranda. "Mulheres brasileiras em tempo de competição eleitoral: seleção de candidaturas e degraus de acesso aos cargos parlamentares". Dados, v. 51 , n. 4, p. 895-940, 2008.

ALVES, José Eustáquio Diniz; CAVENAGHI, Suzana Marta. "Indicadores de desigualdade de gênero no Brasil". Mediações - Revista de Ciências Sociais, v. 18, n. 1, p. 83-105, 2013.

ARAÚJO, Clara. "Potencialidades e limites da política de cotas no Brasil". Revista Estudos Feministas, v. 9, n .1, p. 231-252, 2001

"Partidos políticos e gênero: mediações nas rotas de ingresso das mulheres na representação política". Revista de Sociologia e Política, n. 24, p. 193-215, 2005.

- "Gênero e acesso ao poder legislativo no Brasil: as cotas entre as instituições e a cutura". Revista Brasileira de Ciência Política, v. 2, p. 23-59, 2009.

"Rotas de ingresso, trajetórias e acesso das mulheres ao legislativo: um estudo comparado entre Brasil e Argentina". Revista Estudos Feministas, p. 567-584, 2010.

ARAÚJO, Clara; ALVES, José Eustáquio D. "Impactos de indicadores sociais e do sistema eleitoral sobre as chances das mulheres nas eleições e suas interações com as cotas". Dados, v. 50, n. 3, p. 535-577, 2007.

BALLINGTON, Julie. (Ed.). Equality in Politics: a survey of women and men in Parliaments, $\mathrm{n}$. 54. Geneva: Inter-Parliamentary Union, 2008.

BARREIRA, Irlys; GONÇALVES, Danyelle Nilin. "“Presença" e "ausência” de candidatas: mapeando representações de dirigentes partidários". In: ALVES, José Eustáquio Diniz; PINTO, Céli Regina Jardim; JORDÃO, Fátima (Orgs.). Mulheres nas eleições 2010. São Paulo: ABCP/Secretaria de Políticas para as Mulheres, 2012. p. 315-336.

BINDER, Sarah A. Minority Rights, Majority Rule: partisanship and the development of congress. Cambridge; New York: Cambridge University Press, 1997.

BRASIL. Regimento Interno da Câmara dos Deputados. Aprovado pela Resolução n. 17, de 1989. Brasília, Câmara dos Deputados, Centro de Documentação e Informação.

1214 Estudos Feministas, Florianópolis, 25(3): 1199-1218, setembro-dezembro/2017 
Disponível em: http://www2.camara.leg.br/legin/fed/rescad/1989/ resolucaodacamaradosdeputados-17-21-setembro-1989-320110-normaatualizadapl.html. Acesso em: 05/06/2014.

BRASIL. Código de Ética e Decoro Parlamentar da Câmara dos Deputados. Centro de Documentação e Informação, Coordenação de Publicações, Brasília, 2002. Disponível em: http://www2.camara.leg.br/a-camara/estruturaadm/eticaedecoro/arquivos/ Codigo\%20de\%20Etica\%20da\%20CD.pdf. Acesso em: 05/06/2014.

CHILDS, Sarah; KROOK, Mona Lena. "Should feminists give up on critical mass? A contingent yes". Politics \& Gender, v. 2, n. 04, p. 522-530, 2006.

COX, Gary; MCCUBBINS, Matthew D. Legis/ative Leviathan: party government in the House. Berkeley: University of California Press, 1993.

. Setting the Agenda: responsible party government in the U.S. House of Representatives. New York: Cambridge University Press, 2005.

CRIADA sob protestos, comissão da mulher na Câmara será presidida pelo PR. "Política", UOL Notícias, 28/04/2016. Disponível em: https://noticias.uol.com.br/politica/ultimasnoticias/2016/04/28/nova-comissao-da-mulher-na-camara-sera-presidida-pelo-pr.htm.

DAHLERUP, Drude. "De una pequeña a una gran minoria: uma teoria de la 'masa crítica' aplicada al caso de las mujeres en Escandinávia". Debate feminista, n. 8, 1993.

"The story of the theory of critical mass". Politics and gender, 2006.

FIGUEIREDO, Argelina; LIMONGI, Fernando. "Bases institucionais do presidencialismo de coalizão". Lua Nova, v. 44, p. 81-106, 1998.

GOMES, Larissa Peixoto Vale. "Elegendo mulheres: ideologia partidária, feminismo e inclusão de mulheres na política". Revista Eletrônica de Ciência Política, v. 7, n. 1, 2016.

HEATH, Roseanna; SCHWINDT-BAYER, Leslie; TAYLOR-ROBINSON, Michelle. "Women on the sidelines: women's representation on committees in Latin American legislatures". American Journal of Political Science, v. 49, n. 2, p. 420-436, 2005.

KANTER, Rosabeth Moss. "Some effects of proportions on group life: skewed sex ratios and responses to token women". The American Journal of Sociology, n. 82. v. 5, p. 965-990, 1997.

KANTHAK, Kristin; KRAUSE, George A. The Diversity Paradox: parties, legis/atures, and the organizational foundations of representation in America. New York: Oxford University Press, 2012.

KERGOAT, Danièle. "Divisão sexual do trabalho e relações sociais de sexo". In: HIRATA, Helena et al. (Orgs.). Dicionário crítico feminino. São Paulo: EDUNESP, 2009. p. 67-75.

LOVENDUSKI, Joni. "Women and politics: minority representation or critical mass?". Parliamentary Affairs, n. 54, v. 4, p. 743-758, 2001.

MACAULAY, Fiona. "Cross-party alliances around gender agendas: critical mass, critical actors, critical structures, or critical junctures?". United Nations Expert Group Meeting on Equal Participation of Women and Men in Decision-Making Processes, with Particular Emphasis on Political Participation and Leadership, 2005.

MACKAY, Fiona; KENNY, Meryl; CHAPPELL, Louise. "New Institutionalism Through a Gender Lens: towards a feminist institutionalism?". International Political Science Review, n. 31, v. 5, p. 573-588, 2010.

MATOS, Marlise. "Teorias de gênero ou teorias e gênero? Se e como os estudos de gênero e feministas se transformaram em um campo novo para as ciências". Revista Estudos Feministas, n. 16, v. 2, p. 333-357, 2008.

"Paradoxos da incompletude da cidadania política das mulheres: novos horizontes para 2010". Debate: Opinião Pública e Conjuntura Política, v. 2, p. 31-59, 2010. 
"A sub-representação política das mulheres na chave de sua sub-teorização na ciência política". In: PAIVA, Denise (Org.). Mulheres, poder e política. Goiânia: Cânone, 2012. p. 11-54.

MATTSON, Ingvar; STRÖM, Kaare. "Parliamentary Committees". In: DÖRING, Herbert (Ed.). Parliaments and Majority Rule in Western Europe. Frankfurt: Campus Verlag, 1995. p. 249-307.

MARX, Jutta; BORNER, Jutta. Parlamentos sensibles al género. El estado de la cuestión en América Latina. Peru: IPU/IDEA, 2011.

MIGUEL, Luis Felipe; FEITOSA, Fernanda. "O gênero do discurso parlamentar: mulheres e homens na tribuna da Câmara dos Deputados". Dados - Revista de Ciências Sociais, v. 52, n. 1, 2009.

MULLER, Gustavo; MEIRELES, Fernando. "O que importa no recrutamento para as comissões permanentes? Partidos, informação e paroquialismo na Câmara dos Deputados (19942010)". In: ENCONTRO DA ABCP, IX, Brasília, 2014.

NEIVA, Pedro; OGANDO, Ana Carolina Freitas Lima. "Women's Issues in the Brazilian Chamber of Deputies: participation in committees and the voting patterns of legislators". In: ENCONTRO DA ASSOCIAÇÃO LATINOAMERICANA DE CIÊNCIA POLÍTICA 5. Buenos Aires, 2010.

O QUE é a Secretaria da Mulher. Disponível em: http://www2.camara.leg.br/a-camara/ estruturaadm/secretarias/secretaria-da-mulher/o-que-e-a-secretaria-da-mulher. Acesso em: 15/03/2015.

O'BRIEN, Diana Z. "Gender and select committee elections in the British House of Commons". Politics and gender, n. 8, p. 178-204, 2012.

OLIVEIRA, Adriana. "A Constituição da Mulher Brasileira: uma análise dos estereótipos de gênero na Assembleia Constituinte de 1987-1988 e suas consequências no texto constitucional". 2012. Tese (Doutorado), Departamento de Direito, Pontifícia Universidade Católica do Rio de Janeiro, Rio de Janeiro.

PALMIERI, Sonia. Gender-sensitive parliaments: a global review of good practice. Geneva: IPU, 2011.

PELA primeira vez, mulher é titular na Mesa Diretora da Câmara. Agência Câmara, 2011. Disponível em: http://www2.camara.leg.br/busca/?q=PELA-PRIMEIRA-VEZ\%2C-MULHERE-TITULAR-NA-MESA-DIRETORA-DA-CAMARA\&O $=$ recent\&V $=$ noticias\&colecao $=$ AGENCIA CAMARA\& $x=0 \& y=0$. Acesso em: 15/03/2015.

PEREIRA, Carlos; MUELLER, Bernardo. "Uma teoria da preponderância do Poder Executivo: o sistema de comissões no Legislativo brasileiro". Revista Brasileira de Ciências Sociais, n. 15, p. 45-67, 2000

PHILLIPS, Anne. The politics of presence. Oxford: Oxford University Press, 1995.

PINHEIRO, Luana Simões. Vozes femininas na política: uma análise sobre mulheres parlamentares no pós-Constituinte. Brasília: Secretaria Especial de Políticas para as Mulheres, 2007.

PINTO, Céli Regina J. Uma história do feminismo no Brasil. São Paulo: Fundação Perseu Abramo, 2003.

PISCOPO, Jennifer. "Inclusive Institutions versus Feminist Advocacy: women's legislative committees and caucuses in Latin America". In: CONGRESSO MUNDIAL de CIÊNCIA POLÍTICA, 23, 2014, Montreal, Canadá.

PITKIN, Hanna F. The Concept of representation. Los Angeles: Berkeley; London: University of California Press, 1967.

PT presidirá quatro comissões da Câmara em 2014. "Política", UOL Notícias, 18/02/2014. Disponível em: http://noticias.uol.com.br/politica/ultimas-noticias/2014/02/18/pt-presidiraquatro-comissoes-da-camara-em-2014-veja-distribuicao-por-partido.htm. Acesso em: $17 / 07 / 2014$.

1216 Estudos Feministas, Florianópolis, 25(3): 1199-1218, setembro-dezembro/2017 
PT vai indicar uma deputada para $4^{a}$ suplência da Mesa. Agência Câmara, 2007. Disponível em: http://www2.camara.leg.br/busca/?wicket:interface=:0:2::.. Acesso em: 15/03/2015.

REZENDE, Daniela Leandro. Qual o lugar reservado às mulheres? Uma análise generificada de comissões legis/ativas na Argentina, no Brasil e no Uruguai. 2015. Tese (Doutorado em Ciência Política), Programa de Pós-Graduação em Ciência Política, Faculdade de Filosofia e Ciências Humanas da UFMG, Belo Horizonte.

; OGANDO, Ana Carolina Freitas Lima. "Achievements and Challenges in the Women's Caucus in Brazil's Lower Chamber (1987-2013)". In: CONGRESSO MUNDIAL DE CIÊNCIA POLÍTICA, n. 24, 2016. Disponível em: https://wc2016.ipsa.org/sites/default/files/ipsa-events/ istanbul2016/papers/paper-48134-2016-07-12-1030.pdf.

ROZA, Vivián; LLANOS, Beatriz; GARZÓN DE LA ROZA, Gisela. Partidos politicos y paridad: la ecuación pendiente. Washington: Inter-American Development Bank, 2010.

SACCHET, Teresa. "Partidos políticos e (sub)representação feminina: um estudo sobre recrutamento legislativo e financiamento de campanhas". In: PAIVA, Denise (Org.). Mulheres, poder e política. Goiânia: Cânone, 2012. p. 159-186.

; SPECK, Bruno W. "Financiamento eleitoral, representação política e gênero: uma análise das eleições de 2006". Opinião Pública, v. 18, n. 1, p. 177-197, 2012.

SANTOS, Fabiano. "Partidos e comissões no presidencialismo de coalizão". Dados, n. 45, v. 2, p. 237-264, 2002.

; PAULA, Carolina Almeida de; SEABRA, Joana. "Cotas e movimentos sociais nas estratégias partidárias de inserção de mulheres na vida parlamentar: os casos do Rio de Janeiro e Ceará nas eleições de $\mathbf{2 0 1 0}$ para a Câmara dos Deputados". In: ALVES, José Eustáquio Diniz; PINTO, Céli Regina Jardim; JORDÃO, Fátima (Orgs.). Mulheres nas eleições 2010. São Paulo: ABCP/Secretaria de Políticas para as Mulheres, 2012. p. 315-336.

; RENNÓ, Lúcio. "The selection of committee leadership in the Brazilian chamber of deputies". The Journal of Legis/ative Studies, n. 10, v. 1, p. 50-70, 2004.

SCHWINDT-BAYER, Leslie A. Political power and women's representation in Latin America. New York: Oxford University Press, 2010.

YOUNG, Iris Marion. Inclusion and Democracy. Oxford: Oxford University Press, 2002.

VIOTII, Maria Luiza Ribeiro. "Declaração e a plataforma de ação da IV Conferência Mundial sobre a mulher: Pequim 1995". In: FROSSARD, Heloísa (Org.). Instrumentos internacionais de direitos das mulheres. Brasília: Secretaria Especial de Políticas para Mulheres, 2006. p. 15-25.

WOMEN in national parliaments. Dados relativos a 01/07/2016. Disponível em: http:// www.ipu.org/wmn-e/arc/classif010716.htm.

[Recebido em 28/08/2015, reapresentado em 07/09/2016 e aprovado em 02/02/2017]

\section{Challenges to women's political representation in The Chamber of Deputies}

Abstract: This article discusses the challenges to gender mainstreaming in the Brazilian Chamber of Deputies. I argue that the demand for the election of more women must be associated to the discussion of the rules and procedures governing their activities, since these can limit it or make it more effective from the perspective of women's representation. Assessing the distribution of resources defined as critical posts (seats in legis/ative committees a, chairmanships of committees and the speakership of the Chamber) among male and female legislators, it can be seen that this occurs unevenly. Nevertheless, the creation of the Secretariat for Women stands out as an important resource. Finally, I argue that the challenge to elect more women should be articulated eith the 
need to ensure that female legislators have access political resources to leverage changes in order to achieve the principle of gender mainstreaming.

Keywords: Gender; Legislative branch; Women's political representation

Daniela Leandro Rezende (danielal.rezende@ufv.br) possui graduação em Ciências Sociais, mestrado (2008) e doutorado em Ciência Política pela Universidade Federal de Minas Gerais. Atualmente é professora no Departamento de Ciências Sociais da Universidade Federal de Viçosa. Tem experiência na área de Ciência Política, atuando principalmente nos seguintes temas: gênero, poder legislativo, política comparada.

1218 Estudos Feministas, Florianópolis, 25(3): 1199-1218, setembro-dezembro/2017 